\title{
Optimizing the Performance of a Manually Operated Groundnut (Arachis hypogaea) Decorticator
}

\author{
A. N. Gitau ${ }^{1 *}$, P. Mboya ${ }^{1}$, B. N. K. Njoroge ${ }^{2}$, M. Mburu ${ }^{3}$ \\ ${ }^{1}$ Department of Environmental and Biosystems Engineering, University of Nairobi, Nairobi, Kenya \\ ${ }^{2}$ Department of Civil and Construction Engineering, University of Nairobi, Nairobi, Kenya \\ ${ }^{3}$ Department of Plant Science and Crop Protection, University of Nairobi, Nairobi, Kenya \\ Email: "gitauan@yahoo.co.uk, ayub.gitau@uonbi.ac.ke
}

Received January 14, 2013; revised February 15, 2013; accepted March 7, 2013

\begin{abstract}
Shelling of groundnut pods using manual decorticators in Kenya is characterized by high kernel breakages and low shelling efficiencies. As a result, farmers get low income due to low cost of broken kernels and a lot of time is lost in the tedious shelling operation. To overcome this problem, pertinent parameters that influence shelling efficiency of manually operated groundnut decorticators were identified. Two manually operated decorticators were tested and modifications done on one of the decorticators to optimize its technical performance. Results of machine performance tests showed that for WBS (Wooden beater sheller) at a feed rate of $30 \mathrm{~kg} / \mathrm{hr}$ and $22.6 \mathrm{~mm}$ clearance, shelling efficiency increased with decrease in moisture content for all the groundnut varieties. The highest shelling efficiency was $55.3 \%$ for ICGV 99568, 39.2\% for ICRISAT Groundnut Variety (ICGV) 90704 and 29\% for ICGV 12991 at moisture content of $5.92 \%$ wb. For RBS (Rod beater sheller) at a feed rate of $30 \mathrm{~kg} / \mathrm{hr}$ and $22.6 \mathrm{~mm}$ clearance, the highest shelling efficiency was 58.3\% for ICGV 99568, 42.7\% for ICGV 90704 and 35\% for ICGV 12991 at moisture content of 7\% wb. Identification of the pertinent parameters showed that pod moisture content, clearance and sieve size influence performance of manually operated groundnut. Theoretical predictive models developed were optimized which showed that a maximum shelling efficiency of $88.73 \%$ can be achieved with percent damage of $4 \%$ when the sieve size is $11 \mathrm{~mm}$ and clearance is $16 \mathrm{~mm}$ with a regression coefficient of over $85 \%$. With the modifications done on the WBS decorticator, the highest shelling efficiency of $87 \%$ was obtained at a clearance of $10 \mathrm{~mm}$ for ICGV 99568 which is the largest in size from the three varieties. The shelling efficiency of the modified decorticator is far above those of the RBS and WBS because the sieve sizes and clearances of the later were not optimized. The results of the theoretical optimization of the manually operated groundnut decorticator implies that farmers who shell for seeds can now obtain more seeds shelled with low breakage and therefore will get more income.
\end{abstract}

Keywords: Decorticator; Shelling; Efficiency; Optimization; Clearance; Groundnut; Varieties

\section{Introduction}

Groundnut (Arachis hypogaea) is a species in the family Fabaceae native to South America [1]. Its seed contains about $63 \%$ carbohydrate, $19 \%$ protein and $6.5 \%$ oil [2]. As the groundnut seed is contained in pod, which is usually developed underground, the pod is harvested by pulling or lifting the plant manually or by using a hoe as the mechanization system [3]. The pods are stripped from the haulms, dried, stored and processed. Shelling is a fundamental step in groundnut processing as it allows the kernels and hull to be used as well as other post harvesting technologies to take place such as oil extraction or in hull briquetting [4]. Shelling can generally be done by hand or machines. Hand shelling is the process in which the pod is pressed between the thumb and first finger so

${ }^{*}$ Corresponding author. that the kernel is released. It is the most predominantly used method in Kenya's smallholder agriculture. While hand shelling keeps the rate of Kernel breakage low, it is labour intensive, energy requirement is high [5] and leads to "sore thumb syndrome" when large quantities are handled. A decorticator is a machine for stripping the husk off kernels in preparation for further processing, storage or use as food. The machine can dramatically reduce the labour costs associated with decortications, cleaning and preparing groundnuts for further processing. Decorticators are basically classified as manual or motorized. Manual decorticators are powered by human hand while motorized decorticators are powered by a motor or an engine. Optimizing the performance of a manually operated groundnut decorticator is important so that the shelling efficiency is set at maximum possible and kernel breakage set at minimum possible. Manual shelling of 
groundnut is a time-consuming and tedious operation [6]. The few existing manual decorticators in Kenyan farms are imported and out of reach of the rural peasant farmers who are characterized by small holdings and low income. The power requirement of such decorticators is high and hence, the prime mover is very expensive. [4] developed and evaluated a hand operated groundnut decorticator and found out that the amount of groundnuts shelled from one hectare per man day is $14 \mathrm{Kg}$.

\section{Materials and Methods}

\subsection{Identification of the Pertinent Parameters}

Table 1 provides the pertinent parameters affecting the performance of groundnut decorticator.

\subsection{Determination of Physical Properties of the Nuts}

A bulk quantity of the pods of each of the three groundnut varieties used in this study were obtained from ICRISAT farms in Alupe, western Kenya. The pods were cleaned using the cyclone separator to remove dust and other unwanted materials. The varieties were referred to as ICGV 12991, ICGV 90704, and ICGV 99568. 100 pods from each variety were randomly selected and put in the bowls. For each pod, the axial dimensions of length, major diameter and minor diameter were measured using the vernier callipers reading to $0.05 \mathrm{~mm}$ and readings recorded. 1000 pod weight was determined by physically counting 1000 pods and then weighing in the electronic balance. Weight measurement was replicated three times and average weight compared. For determination of angle of repose, a pod was placed on the $70 \mathrm{~mm}$ by $70 \mathrm{~mm}$ metal sheet and one side of the sheet metal lifted until the pod just rolled down. The angle of the tilt was then measured using angle protractor and recorded. This was repeated for 10 pods and the average determined for each of the varieties. The bulk density of the pods was determined using the AOAC (1980) recommended method. This involved filling $1000 \mathrm{~cm}^{3}$ plastic container with the pods and then weighing the pods. The

Table 1. Pertinent parameters affecting efficiency of groundnut decorticators.

\begin{tabular}{cc}
\hline Parameters & Source \\
\hline Feeding rate & {$[7] ;[8]$} \\
Moisture content & {$[9] ;[12]$} \\
Variety & {$[8] ;[11]$} \\
Percentage of matured nuts & {$[10]$} \\
Drying method & {$[9]$} \\
Rotations per minute & {$[7] ;[8] ;[12]$} \\
\hline
\end{tabular}

bulk density was calculated by dividing the weight by the volume. The pods were conditioned using the method of [10]. This involved soaking of the pods in clean water for a period of $48 \mathrm{~h}$. At the end of soaking, the pods were spread out in thin layer to dry in natural air for about $8 \mathrm{~h}$. The pods were then sealed in marked polythene bags and stored in that condition for a further $24 \mathrm{~h}$. This enabled a stable and uniform moisture content of the pods to be achieved. The moisture content of the kernels was determined using electrical moisture meter. In this method, $100 \mathrm{~g}$ of nuts were placed in the moisture meter and moisture content read. Variation of moisture content was achieved through drying of the pods in the tray drier. Measurements of the moisture content using the moisture meter were taken at intervals of 5 minutes during the first two readings and intervals of 10 minutes for the other three readings. All the readings were recorded and mean and standard deviations determined.

\subsection{Description of the Decorticators}

Figure 1 shows the shelling unit of the wooden beater decorticator. The overall dimensions of the rod beater decorticator are: length of $800 \mathrm{~mm}$, width of $250 \mathrm{~mm}$ and height of $940 \mathrm{~mm}$. The shelling unit consists principally of a rotating cylinder and a stationary concave sieve. The cylinder is $190 \mathrm{~mm}$ in diameter and $200 \mathrm{~mm}$ in length. Twelve shelling metal bars each of $10 \mathrm{~mm}$ diameter and $200 \mathrm{~mm}$ long are mounted uniformly on the cylinder surface and parallel to its axis.

Figure 2 shows the wooden beater decorticator. The decorticator is powered manually and operates in the same manner as rod beater decorticator except that the impact, shear and compressive forces and tangential force are provided by wooded bars. The overall dimensions of the decorticator are: length of $745 \mathrm{~mm}$, width of $270 \mathrm{~mm}$ and height of $1250 \mathrm{~mm}$. A description of two essential units of the decorticator: the shelling and clean ing units are given in the following sections. The shelling

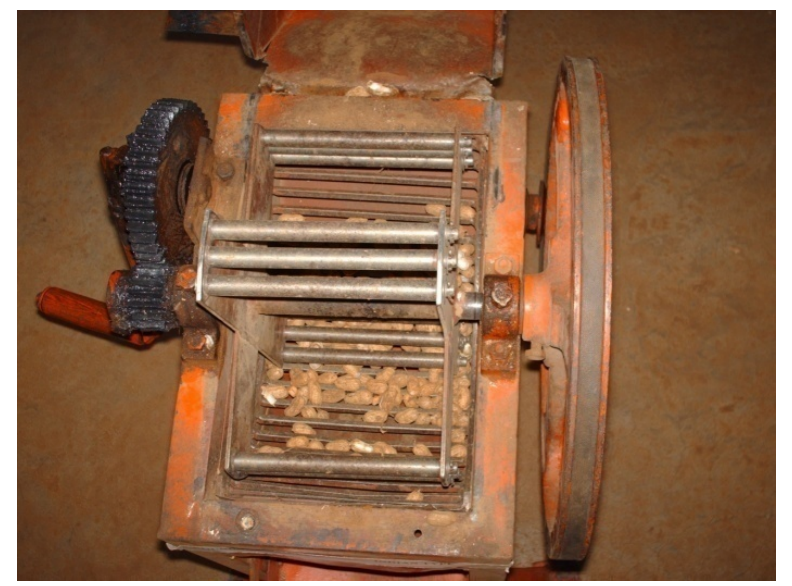

Figure 1. Shelling unit of rod beater decorticator. 


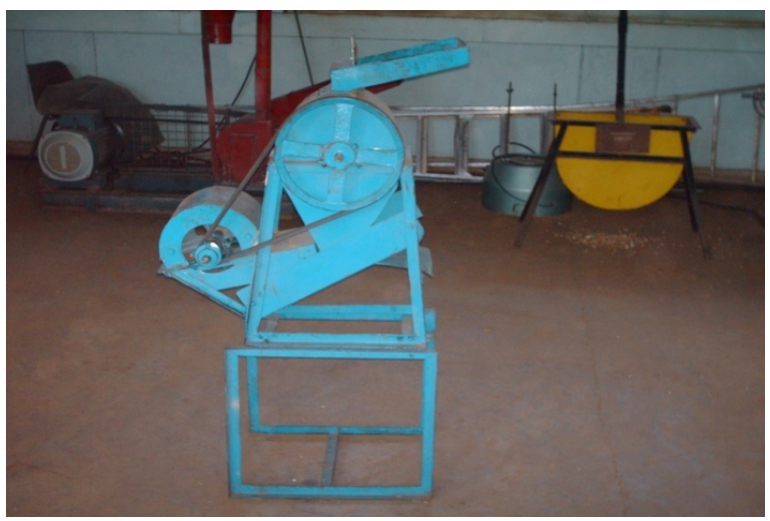

Figure 2. Wooden beater decorticator.

unit consists principally of a rotating cylinder and a stationary concave sieve. The cylinder is $160 \mathrm{~mm}$ in diameter and $380 \mathrm{~mm}$ in length. Four wooden bars are mounted uniformly on the cylinder surface and parallel to its axis.

\subsection{Testing of Decorticators Performance}

A known weight of groundnut pods were manually loaded in the hopper and the decorticator was set to run at clearance settings of $12 \mathrm{~mm}, 14 \mathrm{~mm}$ and $16 \mathrm{~mm}$ and sieve sizes of $12 \mathrm{~mm}, 13 \mathrm{~mm}$ and $15 \mathrm{~mm}$. Before the groundnut pods were released into the shelling chamber, the decorticator was run empty to stabilize the rotation. At each clearance and sieve size setting, groundnut pods were continuously fed to the decorticator for about $3 \mathrm{~min}$. The weight of the pods that were completely shelled and unbroken, completely shelled but broken, partially shelled and unbroken, partially shelled and broken and the weight of unshelled pods were determined at the end of each run. The quantity of shells winnowed out and those collected with the seeds were noted. The performance of the groundnut decorticators was determined in terms of shelling efficiency and kernel damage. The shelling efficiency and kernel damage were calculated using the following formula:

$$
\begin{aligned}
& \text { Shelling efficiency (\%), } S_{e}=\frac{W_{k}}{W_{t}} * 100 \\
& \text { Percent kernel damage (\%), } \quad D=\frac{W_{b}}{W_{k}} * 100
\end{aligned}
$$

where: $W_{k}=$ Weight of kernels shelled including broken kernels; $W_{t}=$ Total weight of kernels fed into the decorticator; $W_{b}=$ Weight of broken kernels. For each run of shelling, the variety, clearance, sieve size, moisture content, shelling efficiency and percent kernel damage were recorded.

\subsection{Optimizing the Performance of the Decorticator}

Optimization of the performance of the decorticator was done using the weighting method of goal programming technique. In this method, the model is optimized using one goal at a time such that the optimum value of a higher priority goal is never degraded by a lower priority goal. Shelling efficiency was the higher goal while percentage damage was the lower goal.

\section{Results and Discussion}

\subsection{Physical Properties of the Nuts}

Physical properties of groundnuts play an important role in the determination of decorticator features and performance characteristics. The pod size governs the clearance between shelling unit and sieve rollers that would result in effective shelling operation. The true and bulk densities, porosity and coefficient of friction influence the pressures exerted on hopper walls and flow through the orifice. The one thousand pod weight was used for the theoretical determination of the pod's effective diameter and the angle of repose was used to determine the hopper inclination. Values of the physical properties of various varieties of groundnut determined are presented in Table 2. The maximum, minimum and average values are reported with their standard deviation.

\begin{tabular}{|c|c|c|c|c|}
\hline \multirow{2}{*}{$\begin{array}{l}\text { Physical } \\
\text { Properties }\end{array}$} & \multicolumn{4}{|c|}{ Values } \\
\hline & Maximum & Minimum & Mean & SD \\
\hline \multirow{3}{*}{$\begin{array}{c}\text { Axial } \\
\text { Dimension-Length } \\
(\mathrm{mm})\end{array}$} & 25.10 & 14.95 & 21.10 & 1.966 \\
\hline & 34.90 & 15.35 & 26.25 & 5.000 \\
\hline & 34.55 & 16.05 & 26.72 & 3.820 \\
\hline \multirow{3}{*}{$\begin{array}{l}\text { Major Diameter } \\
\text { (mm) }\end{array}$} & 12.85 & 8.65 & 11.02 & 0.720 \\
\hline & 16.95 & 10.25 & 13.31 & 1.620 \\
\hline & 15.90 & 10.65 & 13.24 & 0.960 \\
\hline \multirow{3}{*}{$\begin{array}{l}\text { Minor Diameter } \\
\text { (mm) }\end{array}$} & 11.65 & 8.55 & 9.97 & 1.160 \\
\hline & 10.95 & 5.65 & 9.21 & 1.330 \\
\hline & 13.50 & 8.85 & 11.358 & 1.295 \\
\hline \multirow{3}{*}{$\begin{array}{l}\text { Bulk Density } \\
\qquad\left(\mathrm{Kg} / \mathrm{m}^{3}\right)\end{array}$} & 760.40 & 508.50 & 690.42 & 100.20 \\
\hline & 720.90 & 490.90 & 672.78 & 98.40 \\
\hline & 680.70 & 410.60 & 589.22 & 130.80 \\
\hline \multirow{3}{*}{$\begin{array}{l}1000 \text { Pod Weight } \\
\text { (g) }\end{array}$} & 572.10 & 560.90 & 569.70 & 1.220 \\
\hline & 582.50 & 560.70 & 570.40 & 2.350 \\
\hline & 591.40 & 569.30 & 575.80 & 3.220 \\
\hline \multirow{3}{*}{$\begin{array}{l}\text { Angle of Repose } \\
\qquad\left(^{\circ}\right)\end{array}$} & 36 & 26 & 30.10 & 3.300 \\
\hline & 35 & 27 & 28.20 & 1.400 \\
\hline & 32 & 25 & 29.40 & 3.200 \\
\hline
\end{tabular}

Table 2. Physical properties of groundnut pods. 
The major diameter is the part of the pod which houses the kernel and is the one used in grading the pods. The mean major diameters were $11.02 \mathrm{~mm}$ for ICGV 12991, $13.31 \mathrm{~mm}$ for ICGV 90704 and $13.24 \mathrm{~mm}$ for ICGV 99568. [12] studied cracking characteristics of walnut and found that the energy for shelling nuts decreases with increase in the geometric mean diameter for the nuts. With the mean major diameter for ICGV 99568 being the largest, the contact with the sieve and the shelling unit is higher which translate to higher shelling efficiency for the same settings. Effective shelling operation requires that the clearance between the rollers for the various varieties should be just smaller by about $2 \mathrm{~mm}$ than the mean major diameter of the pods. This argument would result into effective shelling clearances to be $10 \mathrm{~mm}$ for ICGV 12991, $12 \mathrm{~mm}$ for ICGV 90704 and $13 \mathrm{~mm}$ for ICGV 99568. Apart from clearance and diameter, the other parameters that can affect the breakage of the pods include size, shape, shell thickness and texture which were also reported by [11] and [9].

ICGV 12991 had a mean bulk density of $690 \mathrm{Kg} / \mathrm{m}^{3}$, ICGV 90704 had $672 \mathrm{Kg} / \mathrm{m}^{3}$ while ICGV 99568 had 589 $\mathrm{Kg} / \mathrm{m}^{3}$. The shelling efficiencies for ICGV 12991 are expected to be high as it had high bulk density but the results showed that it was lower. This indicated that other parameters supersede bulk density in influencing the shelling efficiency of the decorticator. This is also true according to the study done by [8] who found out that bulk density is an indicator of savings in storage and transportation space and not shelling efficiency. However, bulk density of groundnut pods can determine the speed in which the pods fall on the shelling chamber. Groundnuts with high bulk density will fall with greater force into the shelling chamber, thus cracking the pods.

\subsection{Machine Performance}

The data obtained were used to calculate shelling efficiency and percent damage for each of the decorticators. The results include the effect of moisture content, decorticator clearance and sieve size on shelling efficiency and percent kernel damage.

\subsection{Wooden Beater Decorticator}

Results of the effect of moisture content on the shelling efficiency of WBS decorticator for the various varieties with a clearance of $22.6 \mathrm{~mm}$ and a feed rate of $30 \mathrm{~kg} / \mathrm{hr}$ are presented in Figure 3. The figure showed that shelling efficiency increased with decrease in moisture content for all the varieties. As a result of this trend, the highest shelling efficiency was 55.3\% for ICGV 99568, 39.2\% for ICGV 90704 and 29\% for ICGV 12991 at moisture content of $5.92 \%$ wb. To achieve the highest shelling efficiency, the pods should be dried to a mois- ture content of $5 \%$ wb. Husks are weakest at this moisture content when subjected to impact, shear and compressive forces and tangential force provided by wooded bars. The results seem also to agree with the observation by [7] that moisture content of groundnut is probably one of the most important crop factor influencing harvesting and post harvest operations for groundnut.

\subsection{Rod Beater Decorticator}

Decorticator clearance significantly influenced the shelling efficiency of the groundnut decorticator for all the varieties and also had significant effect on percent kernel damage [11]. Shelling efficiency is affected by the decorticator clearance such that as the clearance increases, shelling efficiency decreases but the efficiencies are higher for ICGV 90704 and ICGV 99568 as shown in Figure 4. Clearance of the decorticator influences the compressing forces that the nuts experience. As the clearance reduces, the pods are compressed against the sieve with great force thus ensuring shelling. When the size of the pod is big, the relative clearance is reduced and the shelling efficiency increases.

\subsection{Optimization of Performance of Decorticator}

To optimize the performance of the manually operated

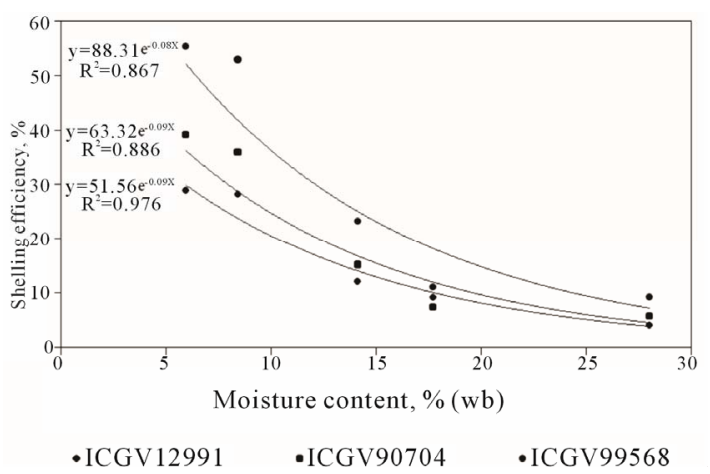

Figure 3. Effect of moisture content on the shelling efficiency of wooden beater decorticator.

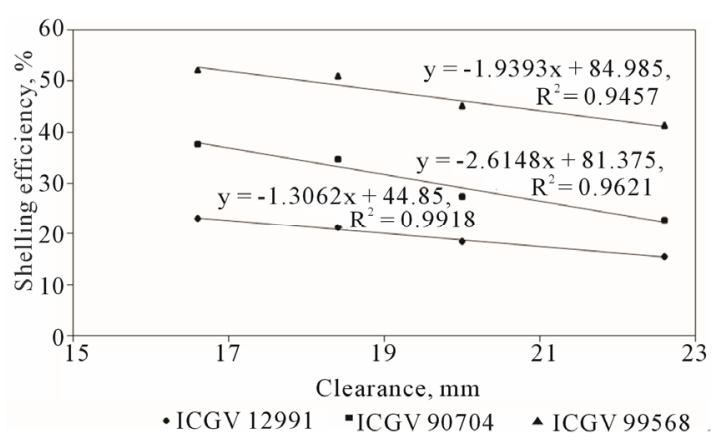

Figure 4. Effect of decorticator clearance on shelling efficiency of RBS decorticator. 
groundnut decorticator, the relationship between shelling efficiency and sieve size and clearance was tested under laboratory condition. For optimization, the parameters affecting the performance majorly the clearance and sieve size were modeled.

\subsection{Relationship of Shelling Efficiency to Sieve Size and Clearance}

Regression analysis was run for two factors namely sieve size and decorticator clearance which can best predict shelling efficiency and percent damage and the model which can best predict the shelling efficiency by sieve size and clearance is given by:

$$
S E=-1.048 S S-0.031 C+99.82
$$

where: $S E$ is shelling efficiency, (\%); $S S$ is sieve size, $\mathrm{mm} ; C$ is clearance, $\mathrm{mm}$.

The ANOVA results show that the model is acceptable from a statistical perspective with a significant $\mathrm{F}$ statistic $(p=0.000)<0.05$ indicating that the model can be used to predict the shelling efficiency. In determining the relative importance of the significant predictors i.e. sieve size and clearance, the standardized coefficients were checked [11]. Even though sieve size and clearance between shelling unit and sieve contribute to the model, sieve size contributes more to the model than clearance because it has a larger absolute standardized coefficient of 0.855. Clearance is a non significant coefficient for clearance $(p=0.955)>0.05$ implying that decorticator clearance does not contribute much to the model.

The strength of the relationship between the model predicted values and the observed values of the dependent variable is such that the $R^{2}$ value is 0.731 showing that more than $70 \%$ of the variation in shelling efficiency is explained by the model. This implies that the model can be used to predict the shelling efficiency.

\subsection{Relationship of Percent Damage to Sieve Size and Clearance}

The estimates of the coefficients of linear model involving the two independent variables that best predict the percent damage is given by Equation (4)

$$
D=0.09 S S-0.881 C+17.094
$$

where $D$ is damage, \%. The model can be used to predict the percent damage from the sieve size selected and the clearance selected because it has a $p$ value of $0.000<$ 0.05 which means the variation explained by the model is not due to chance.

The regression sum of squares is slightly more than residual sum of squares which indicates that more than half of the variation in percent damage is explained by the model [12]. The $\mathrm{R}^{2}$ value for the model was 0.561 showing that about half the variation in percent damage is explained by the model.

\subsection{Optimization of Shelling Efficiency and Percent Damage}

Optimization of technical performance of the decorticator requires maximization of shelling efficiency and minimization of percent damage [12]. Equations (3) and (4) show the separate models for shelling efficiency and percent damage which need to be maximized and minimized respectively. Optimization of the two models using TORA show that the maximum shelling efficiency of $88.73 \%$ can be achieved with percent damage of $4 \%$ when the sieve size is $11 \mathrm{~mm}$ and clearance is $16 \mathrm{~mm}$ [11].

\subsection{Modifications Done on the Decorticator}

Various modifications were done on the tested decorticator which included:

- Change of orientation of sieve holes. Orientation of the sieve holes influences the pressure exerted on the pods. When the pods fall such that the length of the pods run parallel to the sieve holes, the shelling efficiency reduces due to a higher percentage of pods passing through. At the same time when the orientation is against the length of the pods, there is a higher chance for the pods to be shelled. However, this is on assumption that most of the pods fall when the length is vertical.

- Change of sieve hole size. The pressure exerted on the pod shell depends on the force with which the pod is forced through the sieve hole. The smaller the hole size, the greater the pressure thus most pods are broken. However, the size should not be so small that the kernels are broken in the process of shelling.

- Modification of the shelling unit beaters. While the shelling unit had wooden beaters, more breakages occurred due to the hardness of wood. If the material in contact with the pod is made of a softer material, it would bring the effect of the hand which was seen that reduces percentage breakages. Rubber being a softer material was used. Furthermore, the wooden beater had no studs and this enable the pods to slide away without being shelled. For the rubber beater, studs were made which increased the grip and also reduced breakages.

- Tension of the V-belt. The tension in the V-belt influences the amount of torque applied in rotating the shelling unit. If the length of the V-belt is increased, the tension reduces and thus the amount of torque required rotating the shelling unit. The length also should not be such that there is slip when the rotating handle is turned. For the wooden beater decorticator, the tension was so high making the decortications work tiring. 


\subsection{Results for Modified Decorticator}

The results after modifications show that the shelling efficiency increased and the percent breakage reduced due to the modifications regarding sieve hole size and orientation, clearance of the shelling unit, shelling unit beaters and tension of the V-belt. The shelling efficiency for the decorticator varies between the different varieties because of the different physical properties of the pods. Generally, the size of the sieve for the decorticator is inversely proportional to shelling efficiency. However, this is expected as when the sieve size is small, the pod is subjected to high shear and impact forces thus separating the kernel from the pods. With the pods experiencing high shear and impact forces, the kernels also experience the same and so high kernel breakages. To reduce the impact and shear forces, softer but firm material like rubber with cushioning effects is used, percent breakage can be reduced. This is shown by the fact that the kernel breakages are lower for the modified decorticator than neither WBS nor RBS decorticators.

Figure 5 shows that shelling efficiency increases with decrease in clearance. The highest shelling efficiency of $87 \%$ was obtained at a clearance of $10 \mathrm{~mm}$ for ICGV 99568 which is the largest in size from the three varieties. The general efficiency of the modified decorticator is far above those of the RBS and WBS which could only go to a maximum of $55 \%$ because of sieve sizes and clearances which are not optimum. With the clearance increasing, damage is expected to reduce as shear and compression forces are reduced.

\section{Conclusion}

Two manually operated groundnut decorticators were tested and one of them modified. The performance tests showed that the requirements of the farmers including low kernel breakages and high shelling efficiencies could be achieved by the modified decorticator. Two theoretical models relating shelling efficiency and kernel damage to clearance and sieve size were developed. Theoretical

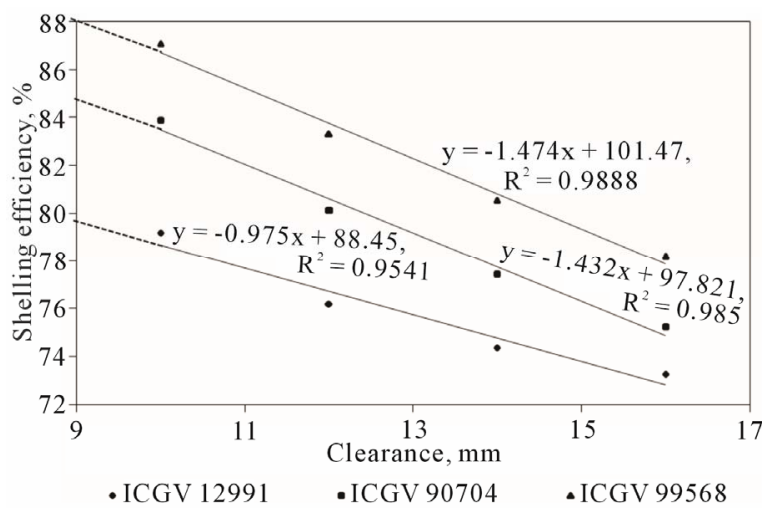

Figure 5. Effect of clearance on shelling efficiency. optimization of the two models using TORA showed that the maximum shelling efficiency of $88.73 \%$ can be achieved with percent damage of $4 \%$ with sieve size of $11 \mathrm{~mm}$ and clearance of $16 \mathrm{~mm}$ with a regression coefficient of over $85 \%$. These values indicated that the machine performance is comparable to that of power operated decorticators. Kernel damage is affected by clearance and sieve size. The kernel damage for the different varieties was significantly different indicating that the varieties have difference in pod resistance to shear and compressive stresses. The important implication of the results of this study is that the modified groundnut decorticator can effectively be used to shell local groundnut varieties. It has also been modified using locally available materials and it is sufficiently versatile for local production and operation.

\section{REFERENCES}

[1] L. P. C. Nautiyal, "National Research Centre for Groundnut (ICAR),” 2007. http://www.icar.org.in/

[2] A. E. Goli, "Bibliographic Review," 1997. In Bambara groundnut.

[3] A. N. Gitau, L. L. Kasisira and Z. M. Mganilwa, "Mechanization Status in the Lake Victoria Basin of East Africa," Australian Journal of Agricultural Engineering, Vol. 1, No. 5, 2010, pp. 160-164.

[4] D. M. Nyaanga, M. C. Chemelil, P. K. Kimani, W. K. Kirui and S. K. Musimba, "Development and Evaluation of a Portable Hand Operated Groundnut Sheller," The KSAE International Conference, 27-28 November 2003.

[5] B. K. Kinyanjui, A. N. Gitau and M. K. Mang'oli, "Power Development Planning Model in East Africa," Journal of Strategic Planning for Energy and the Environment, Vol. 31, No. 1, 2011, pp. 43-55.

[6] FAO, "Functionality Systems,” Food Chemistry, Vol. 47, 2010, pp. 277-283.

http://www.fao.org/inpho/content/compend/text/Ch21sec 2.htm

[7] N. Atiku, N. Aviara and M. Hague, "Performance Evaluation of a Bambara Ground-Nut Decorticator,” Agricultural Engineering International: The CIGR Journal of Scientific Research and Development Manuscript, Vol. VI, 2004.

[8] S. K. Jha, A. Singh and A. Kumar, "Physical Characteristics of Compressed Cotton Stalks," Biosystems Engineering, Vol. 99, No. 2, 2010, pp. 205-210. doi:10.1016/j.biosystemseng.2007.09.020

[9] T. A. Liang, L. Chin and J. B. Mitchell, "Modelling Moisture Influence on Macadamia Nut Kernel Recovery," Transactions of ASAE, Vol. 27, No. 5, 1984, pp. 15381541.

[10] G. O. I. Ezeike, "Quasi-Static Hardness and Elastic Properties of Some Tropical Seed Grains and Tomato Fruit," International Agrophysics, Vol. 2, No. 1, 1986, pp. 15-29.

[11] J. A. Xavier, "Study of Macadamia Nut Breakage,” Un- 
published M.Sc. Thesis, UNESP: Reitoria-Portal da Universidade, Botucatu, 1992.

[12] M. A. Koyuncu, K. Ekinci and E. Savran, “Cracking
Characteristics of Walnut,” Biosystems Engineering, Vol. 87, No. 3, 2004, pp. 305-311.

doi:10.1016/j.biosystemseng.2003.11.001 